\title{
Measuring psychometric characteristics of the elderly sensory responsivity questionnaire- A tool for screening sensory processing difficulties in elderly adults
}

\author{
Batya Engel-Yeger \\ University of Haifa, Haifa, Israel \\ Correspondence: Batya Engel-Yeger. Address: University of Haifa, Haifa, Israel. Email: batya@research.haifa.ac.il. \\ Received: December 31, 2012 Accepted: February 15, 2013 Online Published: July 23, 2013 \\ DOI : 10.5430/jnep.v3n10p167 URL: http://dx.doi.org/10.5430/jnep.v3n10p167
}

\begin{abstract}
Background: The function of the sensory systems decreases in the elderly. This may negatively impact the person's performance and independence in daily living. Most studies refer to the decrease in specific modalities and to sensory acuity rather than to general sensory processing in all modalities. Moreover, there is a lack of evaluation tools that focus on these general sensory processing abilities with functional daily life perspective in the elderly population.
\end{abstract}

Objectives: To examine the psychometric characteristics of the Elderly Adult Sensory Sensitivity Questionnaire (ESRQ) - an adapted version of the Sensory Responsiveness Questionnaire (SRQ) version II. The ESRQ aims to screen sensory processing difficulties among elderly adults, as expressed in daily living situations.

Methods: The sample consisted of 361 participants, aged 50-86 years, who were and in good health and functionally independent. Participants were divided into three age groups: 50-59; 60-69 and 70-86. All participants completed a demographic and health status questionnaire and the ESRQ.

Results: Analysis of ESRQ scales revealed five factors, which explained $45.66 \%$ of the total variance. Internal consistency was high for the full questionnaire and moderate to high for each factor. No significant differences were found between the age groups. Women showed significantly higher sensitivity than men in several modalities.

Implications and conclusions: ESRQ may serve as a suitable tool for screening sensory processing difficulties in the elderly. Gender may play a role in sensory processing changes in the elderly. Further studies should examine the psychometric properties of the ESRQ among elderly people with disabilities. Establishing the prevalence of sensory processing difficulties in the elderly may be beneficial for developing and improving intervention strategies to overcome functional deficits.

\section{Key words}

Elderly, Sensory processing, Assessment, Daily life

\section{I ntroduction}

It is well established that in the elderly, the function of the sensory systems decreases. The sensory systems become less sufficient ${ }^{[1]}$ due to degenerative processes in the sensory organs, progressive loss in brain mass, slower conduction of 
nerve impulses and the breakup of links between neurons ${ }^{[2]}$. For example, the destruction of sensory cells in the taste and smell modalities with aging leads to elevated thresholds and deterioration in sensitivity of these sensations ${ }^{[3,4]}$. Likewise, visual acuity deteriorates and visual perception may be impaired, accompanied by a decrease in sensitivity to color and in night vision ${ }^{[4]}$. Auditory functioning in the elderly is manifested in high tone loss, a decrease in speech perception and additional pathologies that lead to difficulties in interpersonal relations and leisure activities ${ }^{[4]}$. As balance decreases with age, the likelihood of a fall increases, since, for example, the duration of unilateral stance and sway during static standing has also been shown to increase as people age ${ }^{[5]}$.

Although such deterioration may be generally expressed in the sensory systems, some researchers argue that it is not always equal in all sensory modalities ${ }^{[6]}$ and that specific modalities are known to be more sensitive to the impact of aging than others. In regard to somatosensory sensations, studies mention that with aging, processing speed as well as the ability to discriminate sensations are reduced ${ }^{[7,8]}$. Kaneko, Asai, and Kanda ${ }^{[9]}$ found that the threshold of pressure perception for static and dynamic stimuli gradually increase with advancing age, and is markedly elevated in people older than 60 years. Reduction also appears in the temperature sensation, as expressed in lower sensitivity to cold stimuli ${ }^{[10]}$.

The literature highlights that gender may affect sensory processing abilities. For example, touch-pressure thresholds differences were found between genders ${ }^{[1]}$. When evaluating trigeminal nerve functions by quantitative sensory testing, thermal detection thresholds were lower among women as compared to men ${ }^{[12]}$.

Moreover, the literature significantly correlates between an individual's sensory processing abilities, functional performance and independence in daily living ${ }^{[13]}$. Sensory processing difficulties may negatively affect the lives of the elderly, increase accident rates, and reduce daily involvement in the family and the community ${ }^{[14]}$. This raises the need for expanding our knowledge about the sensory functioning of elderly people, especially in relation to daily living.

Most studies that evaluate sensory functioning in the elderly refer to specific sensory modalities and to sensory acuity rather than to general sensory processing in all sensory modalities with functional perspective. Moreover, there is a lack of evaluation tools that focus on these general sensory processing abilities in the elderly population.

Brown et al. ${ }^{[15]}$ developed the Adolescent/Adult Sensory Profile (AASP), which measures the sensory processing abilities of adults (17-79 years) by evaluating the frequency of responses to various daily sensory experiences. Sensory processing involves the registration, modulation and the internal organization of sensory input. These abilities shape cognitive perception, emotions and behavior. Sensory processing difficulties are known to dull adaptive responses to environmental demands, negatively impact meaningful engagement in daily occupations and impair well being ${ }^{[16]}$.

The AASP is one of very few tools available for evaluating sensory function in adults. The lack of suitable instruments for assessing sensory responsiveness in adults led to the development the Sensory Responsiveness Questionnaire (SRQ) version II ${ }^{[17]}$. However, as in the Adult Sensory Profile, the SRQ refers to a wide age range but does not specifically characterize sensory responsivity in the elderly. There remains a need for greater knowledge about the unique sensory processing abilities of elderly people, since difficulties in these abilities may lead to a variety of cognitive, motor, visuoperceptual, and communication-related difficulties ${ }^{[18]}$ and thus to isolation, depression and dependence ${ }^{[6]}$. For this reason, a version of the SRQ was specially adapted by the author for use with the elderly population and is referred to as the Elderly Sensory Responsiveness Questionnaire (ESRQ). This adaptation aimed to screen sensory processing difficulties among elderly people as expressed in daily living scenarios. Whereas other sensory questionnaires refer to the frequency at which persons respond to different sensory events ${ }^{[15]}$, the ESRQ evaluates the intensity of person's responses to sensory stimuli in daily life.

\section{The ESRQ- adaptation process}

The adaptation of the ESRQ was conducted in a series of steps. First, following a review of the 58 statements in the SRQ version II, statements that were not relevant to the elderly population were omitted (for example: "Activities in which I am 
spinning, such as riding on a carousel, bother me"; "During my monthly menstrual cycle, I enjoy noise, lights, places crowded with people, the feeling of clothing on my body"). Second, the statements that were kept were shortened and made to refer to the degree that sensory input from different modalities bothers the person, or impairs function. The later was reflected in statements that present common events such as: "It's hard for me to hear a telephone conversation"; "It's hard for me to hear someone talking to me when there are noises around"; "When I get up from a bed/chair, I lose my balance." Further reliability and validity examinations were performed, as described in the Data analysis/Results sections.

The aim of the present study was to explore the ESRQ and examines its psychometric properties, by referring to: face validity; internal consistency and construct validity. The construct validity included the examination of differences in sensory processing abilities between age groups and between both genders.

It is hypothesized that the ESRQ will show good psychometric properties. Its construct validity will also show age and gender impacts on sensory processing abilities.

\section{Material and methods}

\subsection{Participants}

The sample consisted of 361 participants, including 177 men and 183 women, who were 50-86 years old (mean age 64.86 \pm 9.78$)$. All participants were in good health. All participants were living in their private homes in the community while other were living in nursing homes but functioned independently. Exclusion criteria included severe chronic diseases; severe impairments in the nervous system, such as CVA, Parkinson's disease, diabetes; peripheral neuropathy; and treatment with medication that impacts on the function of the central nervous system.

In order to explore aging impacts on sensory processing abilities, participants' age ranged from 50 to 86 years. Participants were divided into three age groups: 50-59; 60-69 and 70-86. Based on the division of Lazer ${ }^{[19]}$ for age groups, people above 50 are considered as "older adults".

Based on Chi-square analysis, significant difference was found between the percentages of men and women in the different age groups $\left(\chi^{2}=6.2, p=.05\right)$. Table 1 summarizes the participants' socio-demographic information.

Table 1. Summary of participants' socio-demographic information:

\begin{tabular}{|c|c|c|c|c|c|}
\hline & & $50-59(n=136)$ & $60-69(n=109)$ & $70+(n=116)$ & Total Sample $(n=361)$ \\
\hline Age $($ Mean \pm SD) & & $55.02 \pm 2.99$ & $64.42 \pm 2.65$ & $76.82 \pm 4.81$ & $64.86 \pm 9.78$ \\
\hline \multirow{2}{*}{ Gender (n) } & Male & 64 & 64 & 50 & 178 \\
\hline & Female & 72 & 45 & 66 & 183 \\
\hline \multirow{4}{*}{ Familial Status \% } & Single & 3.7 & 1.1 & 3.7 & 2.9 \\
\hline & Married & 88 & 76.1 & 42.1 & 68.4 \\
\hline & Widow & 5.6 & 16.3 & 44.9 & 22.5 \\
\hline & Divorced & 2.8 & 6.5 & 9.3 & 6.2 \\
\hline \multirow{2}{*}{$\begin{array}{l}\text { Living with someone or } \\
\text { alone } \%\end{array}$} & with someone & 90.7 & 90.2 & 53.3 & 77.5 \\
\hline & Alone & 9.3 & 9.8 & 46.7 & 22.5 \\
\hline \multirow{2}{*}{ Residence \% } & Private home & 100 & 93.5 & 76.6 & $89.6 \%$ \\
\hline & Nursing home & 0 & 6.5 & 23.4 & $10.4 \%$ \\
\hline
\end{tabular}




\subsection{Instrumentation}

\subsubsection{Demographic and health status questionnaire}

The questionnaire included information about participants' age, gender, familial status, socioeconomic status and place of residence (as private home; nursing home) as well as information about the physical and mental health status, medications and treatments.

\subsubsection{The ESRQ}

This questionnaire aims to screen sensory processing difficulties among elderly people as expressed in daily life. The total questionnaire consisted of 51 items. After performing factor analysis and according to the loading values, 37 items were left. Similar to the SRQ, each item is rated on a five-point Likert scale, ranging from $1=$ not at all to $5=$ very much. A higher score represents higher sensory responsitivty level.

\subsection{Procedure}

After receiving the approval of the Ethics Committee of the University of Haifa, participants were chosen as a convenience sample and signed an informed consent form in the presence of the data collector, in their homes. In this meeting, participants filled the questionnaires in the presence of the study investigator, according to the following order: the demographic and health status questionnaire and the ESRQ.

\subsection{Data analysis}

The statistical analyses were performed using SPSS-17. Alpha Cronbach was calculated for assessing the reliability of the ESRQ total score and subscales scores. For determining the construct validity of the ESRQ, factor analysis with oblimin rotation was performed, with a factor loading above .30 considered acceptable. Two-way MANOVA tested the age and gender effects as well as the age $\mathrm{X}$ gender interaction effect on the different ESRQ scales (This parametric test was used based on the relatively large number of participants in each age group). Chi-square analysis examined whether significant differences exists between the percentages of men and women in the different age groups. The level of significance was set at .05 for all statistical tests.

\section{Results}

\subsection{Psychometric properties of ESRQ}

\subsubsection{Face validity}

A review of the ESRQ items was performed by an expert panel in order to assure face validity of the ESRQ.

\subsubsection{I nternal consistency}

The Alpha Cronbach value for the full questionnaire was .902. Alpha Cronbach values of each factor ranged from moderate to high (see Table 2).

\subsection{Construct validity}

\subsubsection{Factors}

In the first stage a principal component analysis with orthogonal solution was performed in order to explore whether the questionnaires' items are grouped into specific factors. Items with loading lower than .30 were omitted. Then, 37 items were left based on their loading values in the factor analysis procedure (see Table 2). On these 37 items, oblimin rotation was performed, assuming that a relationship exists between the factors. 
According to the factor analysis with oblimin rotation, five factors were found. The explained variance was $45.66 \%$ (see Table 2).

Table 2. Item's loading values for each factor

\begin{tabular}{|c|c|c|c|c|c|}
\hline & $\begin{array}{l}\text { Factor } 1 \\
\text { Visual and Auditory }\end{array}$ & $\begin{array}{l}\text { Factor } 2 \\
\text { Deep Tactile }\end{array}$ & $\begin{array}{l}\text { Factor } 3 \\
\text { Crude Touch }\end{array}$ & $\begin{array}{l}\text { Factor } 4 \\
\text { Taste and Temperature }\end{array}$ & $\begin{array}{l}\text { Factor } 5 \\
\text { Vestibular }\end{array}$ \\
\hline item 1 & .537 & & & & \\
\hline item 2 & .533 & & & & \\
\hline item 3 & .509 & & & & \\
\hline item 4 & .498 & & & & \\
\hline item 6 & .486 & & & & \\
\hline item 7 & .540 & & & & \\
\hline item 8 & .735 & & & & \\
\hline item 10 & .628 & & & & \\
\hline item 11 & .548 & & & & \\
\hline item 12 & .467 & & & & \\
\hline item 13 & & & & -.578 & \\
\hline item 15 & & .478 & & & \\
\hline item 17 & & & & -.383 & \\
\hline item 18 & & & & -.683 & \\
\hline item 19 & & .579 & & & \\
\hline item 20 & & .659 & & & \\
\hline item 21 & & .553 & & & \\
\hline item 22 & & & .393 & & \\
\hline item 23 & & & -.374 & & \\
\hline item 24 & & .344 & & & \\
\hline item 26 & & & & -.318 & \\
\hline item 27 & & & & -.452 & \\
\hline item 28 & & .432 & & & \\
\hline item 29 & & .557 & & & \\
\hline item 30 & & .445 & & & \\
\hline item 32 & & & & -.465 & \\
\hline item 33 & & .345 & & & \\
\hline item 35 & & & -.532 & & \\
\hline item 37 & & & -.454 & & \\
\hline item 41 & & .342 & & & \\
\hline \multicolumn{6}{|l|}{ item 42} \\
\hline item 43 & & & & & .364 \\
\hline \multicolumn{6}{|l|}{ item 44} \\
\hline item 46 & & & & & .550 \\
\hline item 48 & & & & & .927 \\
\hline item 49 & & & & & .874 \\
\hline item 55 & .474 & & & & \\
\hline R2 & 21.76 & 6.89 & 4.87 & 5.83 & 6.31 \\
\hline Alpha Cronbach & .86 & .76 & .73 & .81 & .81 \\
\hline Mean & 2.14 & 1.51 & 2.76 & 2.43 & 2.07 \\
\hline SD & .83 & .56 & 1.21 & .87 & 1.11 \\
\hline
\end{tabular}

\subsubsection{Age impacts on ESRQ scores}

No statistically significant differences were found between the mean ESRQ scores of the different age groups. 


\subsubsection{Genders impacts on ESRQ scores}

Significant differences were found when comparing the mean ESRQ scores of both genders $(\mathrm{F} 1,358=4.71, p<0.001)$, with the women showing higher sensitivity than the men in the vestibular scale $(\mathrm{F} 1,358=14.73, p<0.001)$, and in the taste/ temperature scale $(\mathrm{F} 1,358=15.77, p<0.001)$.

No significant gender $\mathrm{X}$ age group interaction effect was found in the various factors.

Table 3 summarizes the ESRQ scores in the general sample as well as in each gender.

Table 3. Means scores of ESRQ in each gender

\begin{tabular}{|c|c|c|c|c|c|c|c|c|}
\hline & \multicolumn{4}{|c|}{ General sample } & \multicolumn{2}{|l|}{ Men } & \multicolumn{2}{|c|}{ Women } \\
\hline & Minimum & Maximum & Mean & SD & Mean & SD & Mean & SD \\
\hline $\begin{array}{l}\text { Visual and } \\
\text { auditory }\end{array}$ & 1.00 & 4.27 & 2.14 & .82 & 2.09 & .83 & 2.21 & .82 \\
\hline $\begin{array}{l}\text { Tactile - dorsal } \\
\text { column }\end{array}$ & 1.00 & 4.00 & 1.51 & .56 & 1.47 & .51 & 1.55 & .61 \\
\hline $\begin{array}{l}\text { Tactile -spino } \\
\text { thalamic }\end{array}$ & 1.00 & 5.00 & 2.76 & 1.21 & 2.75 & 1.19 & 2.76 & 1.23 \\
\hline $\begin{array}{l}\text { Taste and } \\
\text { Temperature }\end{array}$ & 1.00 & 5.00 & 2.07 & 1.11 & 1.86 & .95 & 2.27 & 1.22 \\
\hline Vestibular & 1.00 & 4.78 & 2.43 & .87 & 2.26 & .76 & 2.59 & .93 \\
\hline
\end{tabular}

\section{Discussion}

The present study introduced the psychometric properties of the ESRQ which is an adapted version of the SRQ that was specially created for screening sensory processing difficulties in the elderly population. The ESRQ was found to have good face validity, good construct validity and high internal consistency. These good psychometric properties suggest that the ESRQ may serve as an appropriate tool for screening sensory processing difficulties among elderly people.

When referring to the ESRQ construct validity, factor analysis revealed five factors which include different groups of modalities: visual and auditory (e.g. "Bright light bothers me"; "Routine environmental noises as refrigerator; air conditioner, bother me"); taste and temperature (e.g. "It bothers me to each spicy food"; "It bothers me to stay in a hot environment"); vestibular (e.g. "It bothers me to stay in high places") and tactile.

Possible explanation for these factors may be found in the physiology of these various modalities. Visual and auditory modalities include "telereceptors" that can sense stimuli from a distance ${ }^{[20]}$. Many studies regarding sensory processing in the elderly refer to visual/auditory modalities and highlight that decrease in visual acuity and increase in hearing thresholds ${ }^{[21]}$, reduce performance levels on tasks of motor speed, executive function and memory ${ }^{[22-24]}$. Studies also emphasize the importance of integration between the visual and auditory systems for adaptive performance since visual and auditory processes are the gateways to higher cognitive functions ${ }^{[25]}$.

Similar section is found in the Short Sensory Profile (SSP) ${ }^{[26]}$ - the short form of the Sensory Profile ${ }^{[27]}$ which aims to profile the effect of sensory processing on child's functional performance in daily life. In the SSP manual, it is mentioned that difficulties in this section, may negatively impact the child's ability to control the environment and to be productive. This may be also relevant to older people with difficulties in processing visual/auditory stimuli. They might need for example a quiet environment in order to concentrate, bright light in order to perform delicate movements. Multisensory cues, as visual and auditory stimuli, may improve performance in the elderly ${ }^{[28]}$. 
Taste and temperature is an interesting combination which appears in daily life in regard to food digestion. The literature about processing abilities in the elderly refers to each of these modalities separately. The reduced sensitivity to temperature in the elderly is even mentioned in cases of heat-related morbidity and mortality ${ }^{[29]}$. Taste disorders (mainly caused by drug use) are common among older people and may have serious consequences on their health status. Recent studies highlight the necessity to assess gustatory function as a part of any comprehensive geriatric assessment ${ }^{[30]}$.

Aging impacts on the vestibular modality are also reported in the literature mainly in relation to incident falls. A recent report demonstrated a strong association between hearing loss and incident falls in the elderly. This may result from aging processes causing cochlear and vestibular dysfunction, poor awareness of the auditory and spatial environment, or mediation through the effects of hearing loss on cognitive load and shared attention ${ }^{[31]}$. This highlights the need to be aware to possible negative interaction between modalities as auditory and vestibular and to their effects on functional impairments.

Interesting division was found in regard to tactile stimuli which divided into two factors: the first included items related to deep tactile stimuli (e.g. "Deep touch or massage bother me") or discriminative touch (e.g. "It bothers me eating food with different diverse textures"). The second included tactile stimuli related to crude touch, tickle or itch (e.g. "It bothers me to wear wool clothing on my body"). This division may have a neurophysiology explanation. Two different sensory tracts are responsible for delivering tactile information into the brain: (1) The dorsal column, which delivers stimuli such as: deep touch; discriminative touch. (2) Spino-thalamic tract, that in addition to delivering temperature and pain, is also responsible for delivering tactile stimuli as crude touch, tickle or itch ${ }^{[32]}$. When referring to elderly people, the literature about the differences in the function of each of these tracts is scars. However, existing reports highlight the functional impacts of the degeneration of these tracts in the elderly. For example, discriminative touch significantly impacts function of daily life. Specifically, the ability to conform to the spatial details of a surface or an object which is essential for discriminating fine spatial features haptically. Deterioration in this ability does not result only from changes in the skin occurring with age, but also from changes in central processing ${ }^{[33]}$. Aging also correlated with elevation in pressure perception threshold, mainly among people older than 60 years, as was previously reported ${ }^{[9]}$.

Nevertheless, although degradation in somatosensory processing is known to occur with age, the central nervous system in the aging population is still capable of plastic changes. This plasticity may compensate for the sensory processing changes and should be taken into consideration in intervention programs for the elderly, which also focus on function maintenance ${ }^{[34]}$.

It is important to mention that each of these tactile systems, as well as the integration between them, may significantly impact other functions, as cognitive and motor functions. For example, it was found that deterioration in tactile sensitivity may affect selective attention in the elderly ${ }^{[8]}$. Shaffer \& Harrison ${ }^{[35]}$ discussed the motor impacts and specifically mentioned that structural and functional declines of the somatosensory system occur with aging and potentially contribute to postural instability in older adults. They emphasized the importance of using reliable and valid sensory evaluations for older adults and to further study the relationship between sensory processing difficulties and function in daily life.

The ability of ESRQ to characterize the person's sensory processing in the different modalities, strengthens its contribution to evaluation and intervention programs that aim to fit the person's specific needs, enrich stimuli and environments to enhance best maintenance, performance and quality of life.

Another aspect of the construct validity referred to age impacts on sensory processing. Interestingly, although neurological studies describe deterioration in sensory functioning among the elderly, especially between the seventh to ninth decades ${ }^{[36]}$, no significant differences were found between the age groups in the mean ESRQ score in the present study. Likewise, Pohl et al. ${ }^{[6]}$ did not find differences in sensory sensitivity levels between middle-aged and older adults. This supports the claim of Zheng et al. ${ }^{[34]}$ mentioned above, regarding plasticity of the central nervous system in the elderly. In addition, the fact that only independent participants with general good health participated in the present study may also 
contribute to this result. This suggests that the ESRQ values may fit the elderly population from the age of 50 and above. However, this issue should be further evaluated in order to determine whether the lack of significant differences found between the age groups was due to the low sensitivity of the questionnaire and whether such differences will be more prominent when evaluating elderly people with disabilities, such as depression and cognitive deterioration.

The present study found difference between genders, with women showing higher sensitivity in the Vestibular and Taste/ Temperature scales. George, Wittmer, Fillingim, \& Robinson ${ }^{[37]}$ found that women had elevated thermal pain sensitivity than men.

In relation to the vestibular and taste modalities, a lack of information exists regarding gender differences, mainly in the elderly. However, very few studies refer to gender differences in sensitivity to other sensory stimuli along life span. For example, a gender-related difference in olfactory sensitivity to androstenone (a steroid found in sweat and urine) has been reported to occur during adolescence. More males than females exhibited anosmia or an increase in androstenone threshold with age ${ }^{[38]}$. Another study which examined olfactory function among healthy African-Americans and Caucasians participants between the ages of 20-40 and 60-80 years found that older persons, regardless of race, had lower smell identification and had increased chemosensory complaints. Women had higher smell sensitivity than men ${ }^{\text {[39] }}$.

Some studies explain that each gender undergoes unique anatomical changes in the brain, leading to different expressions of sensory function ${ }^{[40]}$. MRI studies showed that for women, the width of many regions of the corpus callosum increased until the perimenopausal years, followed by a gradual decrease in width with further aging. In contrast, men exhibited maximum callosal width in their early 20 s, with a relatively rapid decrease thereafter. Research has shown that hormonal changes in elderly women may impact on their sensory systems ${ }^{[36,41]}$. The present study suggests that specific sensory systems are more vulnerable to these effects. The impact of gender should be considered in intervention programs for elderly men and women.

\section{Conclusions}

The ESRQ may serve as a suitable tool for evaluating sensory processing difficulties in the elderly. However, its psychometric properties should be further investigated in order to better understand the impact of age and gender on sensory deficits. Establishing the prevalence of sensory processing difficulties, specifically in elderly people, is of the utmost importance. As was noted in the literature ${ }^{[6,13]}$ older adults can use knowledge about their own sensory processing patterns to organize their homes, their daily routines, and their recreational activities so as to take the best advantage of preferences and effectively reduce aversions. Communities can use data about the sensory processing patterns of older adults to design living arrangements and to inform decisions about driving for older adults and their families. Finally, illumination of this issue may serve as a step in setting a research agenda related to further empirical study and the development of intervention programs based on the differences in sensory processing between typical elderly people and impaired elderly populations, such as patients with Alzheimer's disease.

\section{References}

[1] Campbell VA, Crews JE, Moriarty DG, Zack MM, Blackman DK. Surveillance for sensory impairment, activity limitation, and health-related quality of life among older adults_-United states, 1993-1997. MMWR CDC Surveill Summ. 1999; 48(8): $131-156$. PMid:10634273

[2] Cerella J. Aging and information-processing rate. In Handbook of the psychology of aging J.E. Birren \& K.W. Schaie, Eds. (3rd. ed.) San Diego, CA: Academic Press. 1990: 201-221.

[3] Kennedy O, Law C, Methven L, Mottram D, Gosney M. Investigating age-related changes in taste and affects on sensory perceptions of oral nutritional supplements. Age Ageing. 2010; 39(6): 733-738. PMid:20861088 http://dx.doi.org/10.1093/ageing/afq104

[4] Bonder B, Wagner M. Functional performance in older adults (2nd ed.). Philadelphia: F.A. Davis; 2001. 
[5] Karmakar C, Khandoker A, Begg R, Palaniswami M. Understanding ageing effects using complexity analysis of foot-ground clearance during walking. CMBBE 2012; [Epub ahead of print].

[6] Pohl PS, Dunn W, Brown C. The role of sensory processing in the everyday lives of older adults. OTJR. 2003; $23(3)$ : 99.

[7] Holden JK, Nguyen RH, Francisco EM, Dennis RG, Zhang Z, Tommerdahl M. A novel device for the study of somatosensory information processing. Journal of Neuroscience Methods. 2012; 204(2): 215-220. PMid:22155443 http://dx.doi.org/10.1016/j.jneumeth.2011.11.007

[8] Valeriani M, Ranghi F, Giaquinto S. The effects of aging on selective attention to touch: A reduced inhibitory control in elderly subjects? International Journal of Psychophysiology. 2003; 49(1): 75-87. http://dx.doi.org/10.1016/S0167-8760(03)00094-1

[9] Kaneko A, Asai N, Kanda T. The influence of age on pressure perception of static and moving two-point discrimination in normal subjects. Journal of Hand Therapy. 2005; 18(4): 421-424. PMid:16271689 http://dx.doi.org/10.1197/j.jht.2005.09.010

[10] Stevens J, Choo K. Spatial acuity of the body surface over the life span. Somatosensory Motor Research. 1996; $13(2)$ : 153-166. PMid:8844964 http://dx.doi.org/10.3109/08990229609051403

[11] Berquin AD, Lijesevic V, Blond S, Plaghki L. An adaptive procedure for routine measurement of light- touch sensitivity threshold. Muscle \& Nerve. 2010; 42(3): 328-338. PMid:20665509 http://dx.doi.org/10.1002/mus.21689

[12] Yekta SS, Smeets R, Stein JM, Ellrich, J. Assessment of trigeminal nerve functions by quantitative sensory testing in patients and healthy volunteers. JOMS. 2010; 68(10): 2437-2451.

[13] Smith DL, Aketar AJ, Garraway WM. Proprioception and spatial neglect after stroke. Age and Ageing. $1983 ; 12(1)$ : 63. PMid:6846094 http://dx.doi.org/10.1093/ageing/12.1.63

[14] Nogaki H, Ohba Y, Matsumoto K, Morimatsu M, Fukuoka Y. Statistical analysis of post-stroke patients in a rehabilitation institution. Nihon Ronen Igakkai Zasshi. Japanese Journal of Geriatrics. 1991; 28(5): 678-682. PMid:1753431 http://dx.doi.org/10.3143/geriatrics.28.678

[15] Brown C, Tollefson N, Dunn W, Cromwell R, Filion D. The adult sensory profile: Measuring patterns of sensory processing. AJOT. 2001; 55(1): 75-82. PMid:11216370

[16] Calvert G, Spence C, Stein BE. The handbook of multisensory processes The MIT Press; 2004.

[17] Bar-Shalita T, Seltzer, Z, Vatine JJ, Yochman A, Parush S. Development and psychometric properties of the sensory responsiveness questionnaire (SRQ). Disability \& Rehabilitation. 2009; 31(3): 189-201. PMid:18608365 http://dx.doi.org/10.1080/09638280801903096

[18] Berry P, Mascia J, Steinman BA. Vision and hearing loss in older adults:" double trouble". Care Management Journals. 2004; 5(1): 35-40. PMid:15792329 http://dx.doi.org/10.1891/cmaj.5.1.35.61260

[19] Lazer W. Inside the mature market. American Demographics. 1985; 48(7): 25-43.

[20] Medilexicon. http://www.medilexicon.com/medicaldictionary.php?t=90020 (July 30, 2012, date last accessed).

[21] Lam BL, Christ SL, Zheng DD, West SK, Munoz BE, Swenor BK, Lee DJ. Longitudinal Relationships among Visual Acuity and Tasks of Everyday Life: The Salisbury Eye Evaluation Study. IOVS 2012; [Epub ahead of print]

[22] Rapp PR, Heindel WC. Memory systems in normal and pathological aging. Current Opinion in Neurology. 1994; 7(4): $294-298$. http://dx.doi.org/10.1097/00019052-199408000-00003

[23] Birren JE, Fisher LM. Aging and Speed of Behavior: Possible Consequences for Psychological Functioning. Annual Review of Psychology. 1995; 46: 329-353. PMid:7872732 http://dx.doi.org/10.1146/annurev.ps.46.020195.001553

[24] Rhodes MG. Age-Related Differences in Performance on the Wisconsin Card Sorting Test: A Meta-Analytic Review. Psychology and Aging. 2004; 19(3): 482-494. PMid:15382998 http://dx.doi.org/10.1037/0882-7974.19.3.482

[25] Cliff M, Joyce DW, Lamar M, Dannhauser T, Tracy DK, Shergill SS. Aging effects on functional auditory and visual processing using fMRI with variable sensory loading. Cortex 2012; [Epub ahead of print]. PMid:22578707

[26] McIntosh DN, Miller LJ, Shyu V, Hagerman RJ. Sensory-modulation disruption, electrodermal responses, and functional behaviors. DMCN. 1999; 41: 608-615.

[27] Dunn W. The Sensory Profile: Examiner's Manual. San Antonio, TX: The Psychological Corporation; 1999.

[28] Mahoney JR, Verghese J, Dumas K, Wang C, Holtzer R.. The effect of multisensory cues on attention in aging. Brain Research. 2012; 7(1472): 63-73. PMid:22820295 http://dx.doi.org/10.1016/j.brainres.2012.07.014

[29] Hansen ABP, Nitschke M, Pisaniello D, Newbury J, Kitson A. Older persons and heat-susceptibility: the role of health promotion in a changing climate. Promotion Journal of Australia. 2011; 22: S17-20.

[30] Imoscopi A, Inelmen EM, Sergi G, Miotto F, Manzato E. Taste loss in the elderly: epidemiology, causes and consequences. Aging Clinical Experimental Research 2012; [Epub ahead of print]. PMid:22828477

[31] Lin FR, Ferrucci L. Hearing loss and falls among older adults in the United States. JAMA. 2012; 172(4): 369-371.

[32] Purves D, Augustine GJ, Fitzpatrick D, Katz LC, La Mantia AS, NcNamara JO, Williams SM. Neuroscience, 2nd ed. Sinauer Associates. Inc., Sunderland, Massachusetts, USA; 2001. 
[33] Vega-Bermudez F, Johnson, KO. Fingertip skin conformance accounts, in part, for differences in tactile spatial acuity in young subjects, but not for the decline in spatial acuity with aging. APP. 2004; 66(1): 60-67.

[34] Zheng Zhang EM, Holden JK, Dennis RG, Tommerdahl M.. Somatosensory information processing in the aging population. Frontiers in Aging Neuroscience. 2011; 3: 18. PMid:22163221

[35] Shaffer SW, Harrison AL. Aging of the somatosensory system: A translational perspective. Physical Therapy. 2007; 87(2): 193-207. PMid:17244695 http://dx.doi.org/10.2522/ptj.20060083

[36] Barozzi S, Giuliano D, Giordano G, Cesarani A. Dynamic stabilometric findings in equilibrium disorders of the elderly. Acta Otorhinolaryngologica Italica. 2005; 25(4): 220. PMid:16482979

[37] George SZ, Wittmer VT, Fillingim, RB, Robinson ME. Sex and pain-related psychological variables are associated with thermal pain sensitivity for patients with chronic low back pain. Journal of Pain. 2007; 8(1): 2-10. PMid:17207739 http://dx.doi.org/10.1016/j.jpain.2006.05.009

[38] Hummel T, Krone F, Lundström JN, Bartsch O. Androstadienone odor thresholds in adolescents. Hormones and Behavior. 2005; 47(3): 306-310. PMid:15708759 http://dx.doi.org/10.1016/j.yhbeh.2004.10.007

[39] Jones RE, Brown CC, Ship JA. Odor identification in young and elderly African-Americans and Caucasians. SCDA. 1995; 15(4); 138-143.

[40] Cowell PE, Allen LS, Zalatimo NS, Denenberg VH. A developmental study of sex and age interactions in the human corpus callosum. Developmental Brain Research. 1992; 66(2): 187-192. http://dx.doi.org/10.1016/0165-3806(92)90079-C

[41] Anstey KJ, Luszcz MA, Giles LC, Andrews GR. Demographic, health, cognitive, and sensory variables as predictors of mortality in very old adults. Psychology and Aging. 2001; 16(1): 3. PMid:11302365 http://dx.doi.org/10.1037/0882-7974.16.1.3 